\title{
EDITORIAL
}

\section{Whiplash can have lesions}

\author{
Nikolai Bogduk MD, PhD, DSc
}

$\mathrm{T}$ he prognosis of acute whiplash-associated disorder (WAD) is generally favourable. As a rule, patients do not require sophisticated management. Evidence-based guidelines recommend explanation, reassurance and activation as the only interventions required $(1,2)$. Passive interventions lack an evidence base and are not indicated.

Personal psychological variables are not risk factors for chronicity, but social factors are. Chronicity is greater among patients who engage a lawyer, and to a lesser extent, if they consult a physical therapist or a chiropractor $(3,4)$. For such reasons, WAD has been promoted as a biopsychosocial disorder.

That concept, however, invites medical nihilism. It is easy and convenient to assume that WAD is entirely psychosocial with no biomedical basis. Conviction in the latter can be reinforced by ordering inappropriate diagnostic tests that return a negative result.

Notwithstanding the influence of psychosocial factors, the strongest determinant of chronicity of WAD is intense pain (5). The biopsychosocial concept is detrimental to such patients if the pain is attributed, without valid evidence, to psychosocial factors, and the cause of pain is ignored.

These various precepts are illustrated by the case reports of Johansson (pages 197-199) in the present issue of Pain Research $\mathbb{E}$ Management (6). He describes the plight of three patients with persistent symptoms after a whiplash accident. All had neck pain and/or headache, which is typical of patients with WAD, but each also had other symptoms that should have been recognized as red flag indicators - they were not. Instead, the persisting symptoms were attributed to psychological factors. Under the administrative system under which these patients suffered, one was simply declared fit for work, and the other two were accorded a diagnosis of psychosomatic disorder. Static radiological investigations that returned negative results were used to reinforce these diagnoses.

Trembling in the upper limb, loss of balance and impaired lower limb function imply long tract injury of the spinal cord. Numbness of the tongue is the cardinal feature of neck-tongue syndrome (7), and implies instability of the atlas (8). But instability cannot be diagnosed using static tests; it requires dynamic testing.

When these patients were investigated with functional magnetic resonance imaging, dramatic results were obtained. Imaging showed capsule tears and instability of the lateral atlantoaxial joint, and scar tissue around the odontoid process with cord impingement upon rotation of the head. These abnormalities were confirmed at surgery.

These patients had symptoms and they had pathology. The pathology was perfectly concordant with the symptoms of which they complained. However, those symptoms were dismissed as psychogenic, and the possibility of pathology was ignored.
The plight of these patients underscores the frailty of the psychosocial model of WAD. Although it may be attractive and convenient to apply a psychological diagnosis, doing so is neither reliable nor valid. There are no objective diagnostic criteria. A psychological diagnosis, to the exclusion of a biomedical one, is no more than an opinion, and when offered by administrative tribunals or their agents is, no more than a self-serving or punitive opinion.

The complement to this opinion is exclusion of a biomedical cause of pain. In the case of chronic WAD that is not a simple matter. Conventional medical imaging lacks sensitivity for capsular and intra-articular injuries of the spine, and static imaging does not reveal movement abnormalities. Consequently, computed tomography and magnetic resonance imaging are not appropriate tests by which to rule out pathology. The pursuit of pathology in chronic WAD requires specialized and sophisticated methods. Moreover, it requires that practitioners and assessors be aware of what can be performed and what is appropriate. That demands more responsibility of them than to be dismissive in the light of a reportedly normal computed tomography scan or magnetic resonance imaging.

In this regard, Johansson provides a salient illustration that functional magnetic resonance imaging is one such possible investigation. It is not indicated for every patient with WAD, but it seems very appropriate for patients with signs of high cervical lesions, symptoms of long tract compromise and numbness of the tongue.

The questions that Johansson's report raises are how many patients in the past and how many current patients with WAD have pathology that has not been pursued? How many have been condemned unjustly to a psychological label, because of opinion?

\section{REFERENCES}

1. Peeters GG, Verhagen AP, de Bie RA, Oostendorp RAB. The efficacy of conservative treatment in patients with whiplash injury: A systematic review of clinical trials. Spine 2001;26:E64-73.

2. Australian Acute Musculoskeletal Pain Guidelines Group. Evidence-based management of acute musculoskeletal pain.

$<$ http://www.nhmrc.gov.au/publications/_files/cp94.pdf> (Version current at January 5, 2006)

3. Osti OL, Gun RT, Abraham G, Pratt NL, Eckerwall G, Nakamura H. Potential risk factors for prolonged recovery following whiplash injury. Eur Spine J 2005;14:90-4.

4. Gun RT, Osti OL, O'Riordan A, Mpelasoka F, Eckerwall CG,

Smyth JF. Risk factors for prolonged disability after whiplash injury: A prospective study. Spine 2005;30:386-91.

5. Scholten-Peeters GG, Verhagen AP, Bekkering GE, et al. Prognostic factors of whiplash-associated disorders: A systematic review of prospective cohort studies. Pain 2003;104:303-22.

6. Johansson $\mathrm{BH}$. Whiplash injuries can be visible at surgery. Pain Res Manage 2006;11:197-99.

7. Lance JW, Anthony M. Neck-tongue syndrome on sudden turning of the head. J Neurol Neurosurg Psychiatry 1980;43:97-101.

8. Bogduk N. An anatomical basis for the neck-tongue syndrome. J Neurol Neurosurg Psychiatry 1981;44:202-8. 


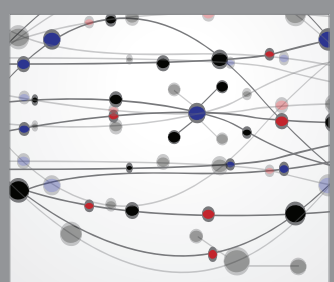

The Scientific World Journal
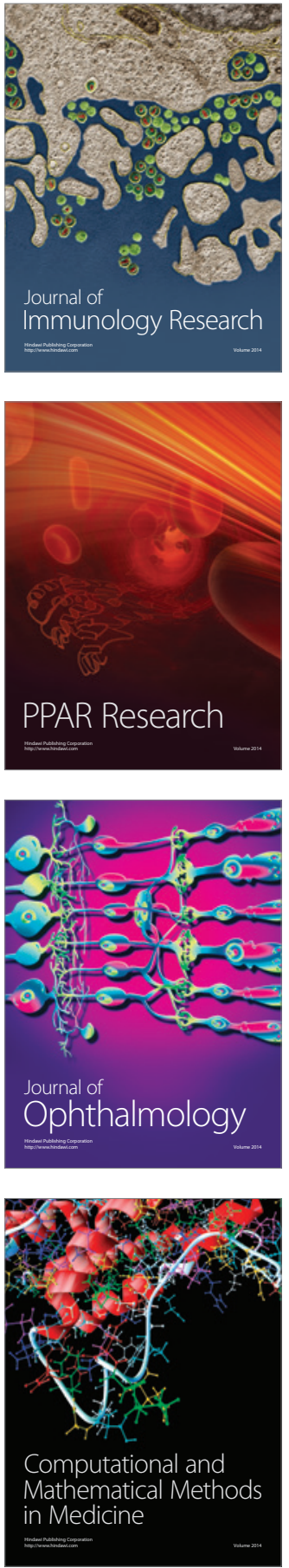

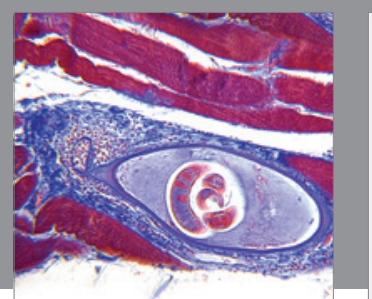

Gastroenterology Research and Practice

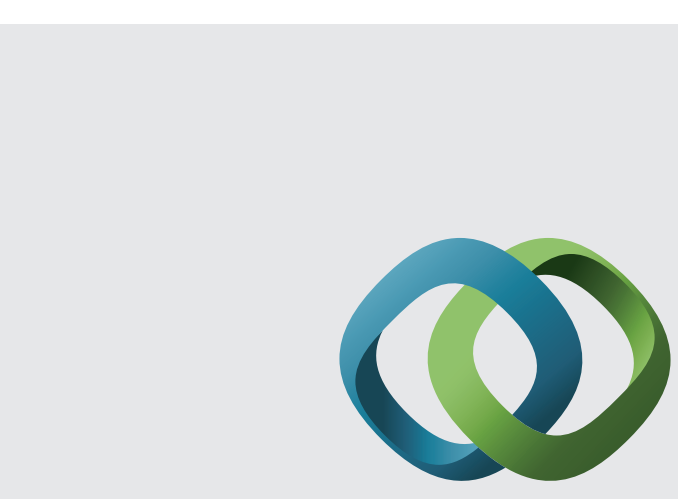

\section{Hindawi}

Submit your manuscripts at

http://www.hindawi.com
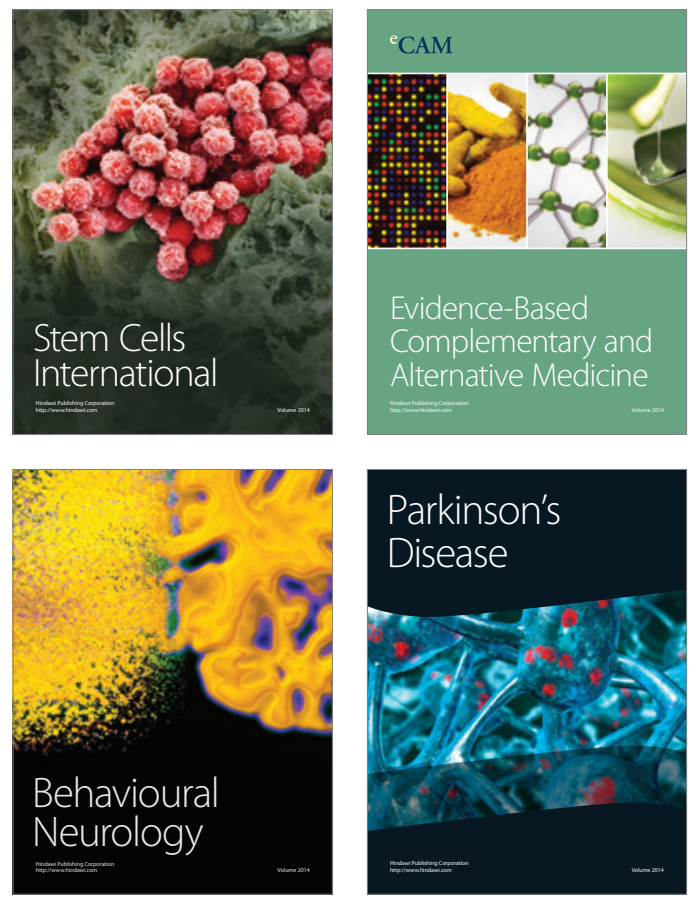
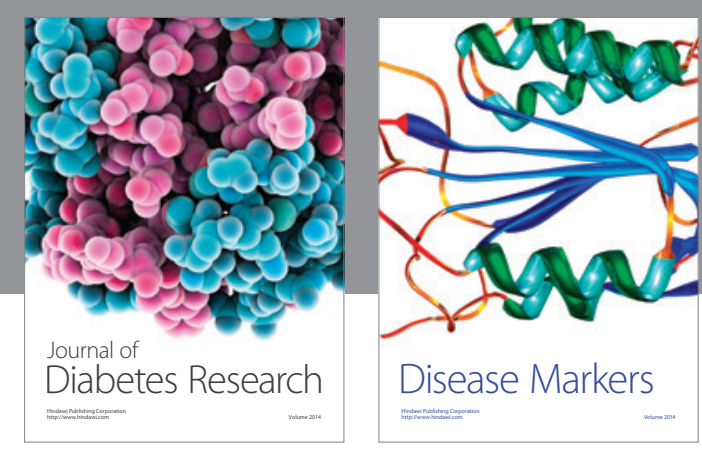

Disease Markers
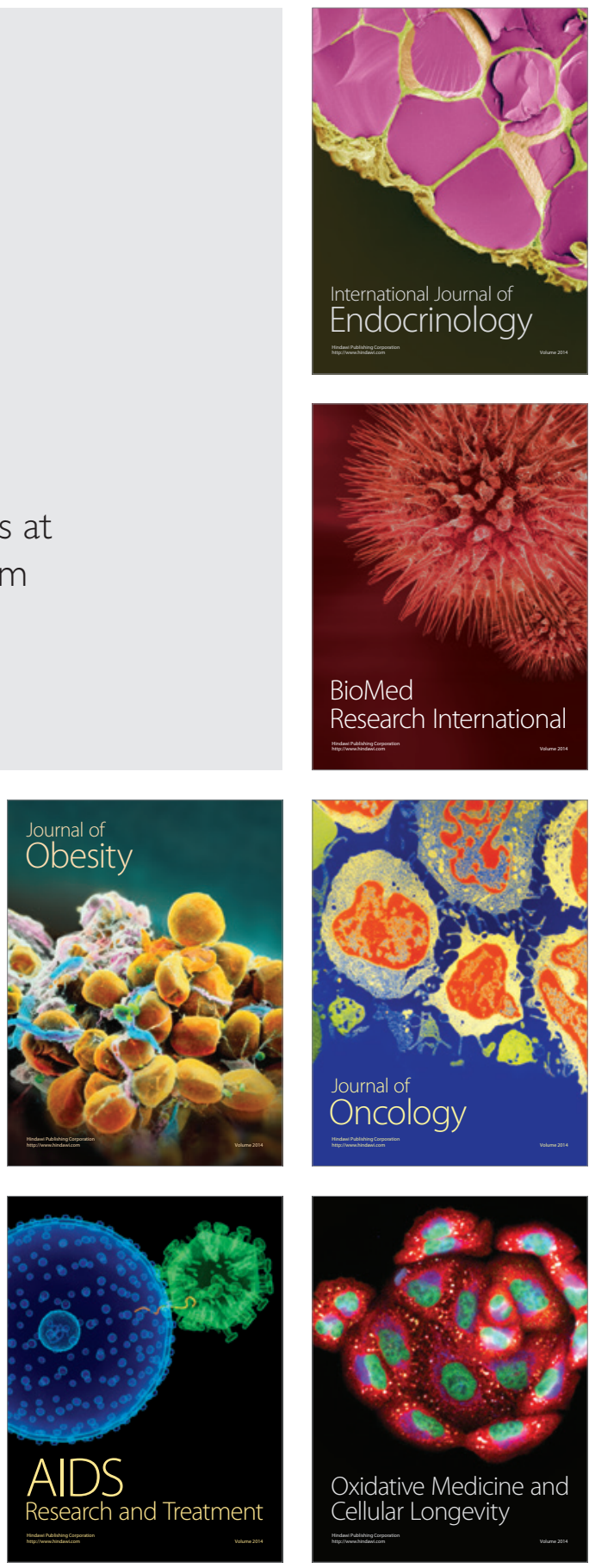